\title{
TEN YEARS OF NEW INJURY SEVERITY SCORE (NISS): IS IT A POSSIBLE CHANGE?
}

\author{
Lilia de Souza Nogueira ${ }^{1}$ \\ Cristiane de Alencar Domingues ${ }^{1}$ \\ Miriam de Araújo Campos ${ }^{2}$ \\ Regina Márcia Cardoso de Sousa ${ }^{3}$
}

Nogueira LS, Domingues CA, Campos MA, Sousa RMC. Ten years of New Injury Severity Score (NISS): is it a possible change? Rev Latino-am Enfermagem 2008 março-abril; 16(2):314-9.

The article is a bibliographic review which intends to present the actual range of researches comparing the Injury Severity Score (ISS) and the New Injury Severity Score (NISS). Databases were searched using the keyword NISS, with 42 articles, 23 of which didn't compare the two indexes. Most part of the 19 selected articles showed that NISS has been more accurate in predicting the outcomes (dependent variables) than ISS, moreover in severe and specific trauma. Studies with populations between 1,000 and 10,000 resulted in NISS-favorable results, whereas studies with populations larger than 10,000 or smaller than 1,000 showed either NISS-favorable results or no difference between the two groups. However, there were no studies showing ISS-favorable results. These results and the easier calculation of NISS lead to a future replacement of ISS by NISS.

DESCRIPTORS: trauma severity indexes; injury severity score; wounds and injuries

\section{DIEZ AÑOS DEL NEW INJURY SEVERITY SCORE (NISS): ¿CAMBIO POSIBLE?}

Estudio de revisión bibliográfica cuyo objetivo es presentar el panorama sobre investigaciones que utilizan el Injury Severity Score (ISS) en comparación con el New Injury Severity Score (NISS). Las búsquedas fueron realizadas en las bases de datos, utilizando el término NISS. Encontrados 42 artículos, 23 de los cuales no realizaron la comparación de los índices en cuestión. Gran parte de los 19 artículos seleccionados, encontraron que el NISS al ser comparado, mostró una mejor relación con los resultados del ISS, principalmente en lesiones graves y específicas. Para estudios cuyas muestras variaron entre 1.000 y 10.000 casos, se observaron resultados favorables para el NISS. Muestras superiores a 10.000 e inferiores a 1.000 mostraron tanto preferencia como igualdad para el NISS. En ningún estudio el ISS superó al NISS, para el caso del diagnósticos de situaciones analizadas. Estas observaciones y un mejor cálculo del NISS frente al ISS, parecen indicar la futura substitución del ISS por el NISS.

DESCRIPTORES: índices de gravedad del trauma; puntaje de gravedad del traumatismo; heridas y traumatismos

\section{DEZ ANOS DE NEW INJURY SEVERITY SCORE (NISS): POSSÍVEL MUDANÇA?}

Trata-se de revisão bibliográfica, cujo objetivo é apresentar o panorama das pesquisas que utilizam o New Injury Severity Score (NISS) e que o comparam com o Injury Severity Score (ISS). Foram realizadas buscas em bases de dados utilizando-se o termo NISS. Foram localizados 42 artigos, 23 não comparavam os índices em questão. A maioria dos 19 artigos selecionados afirmou que NISS se relacionou melhor com os resultados do que o ISS, principalmente em ferimentos graves e específicos. Em estudos, cuja amostra variou de 1.000 a 10.000 casos, observou-se resultado favorável ao NISS; amostras maiores que 10.000 e menores que 1.000 indicaram ora preferência ao NISS, ora igualdade. Em nenhum estudo o ISS superou o NISS para prever os eventos analisados. Essas observações e maior facilidade do cálculo do NISS em relação ao ISS direcionam a futura substituição do ISS pelo NISS.

DESCRITORES: índices de gravidade do trauma; escala de gravidade do ferimento; ferimentos e lesões

${ }^{1}$ RN, Master's Student, e-mail: lilianogueira@usp.br, crismingues@usp.br. University of São Paulo, School of Nursing, Brazil; ${ }^{2}$ RN, Faculty, University of São Paulo, Medical School, through the Zerbini Foundation, Brazil, e-mail: campos-miriam@uol.com.br; ${ }^{3}$ Associate Professor, University of São Paulo, School of Nursing, e-mail: vian@usp.br 


\section{INTRODUCTION}

Since early times, men have faced wars and catastrophe causing multiple trauma injuries, and face the challenge of appropriately treating these victims for recovery. To assess, prevent and prepare to care for trauma cases, some assessment systems have been developed to check severity and prognoses of victims.

To that end, several severity indexes have been proposed enabling to assess and communicate objectively, using a uniform language, physiological changes, severity of anatomic lesions, and probability of survival of a trauma population.

The terminology "severity of trauma indexes" is defined in Descriptors of Health Science as "system to assess, classify and code lesions". These indexes are, however, more explicitly defined as numerical classifications connected with one or more characteristics of trauma or of victims, which are determinants of the clinical outcome observed in patients. Thus, there is a numerical expression in the indexes of trauma severity, and these are related to the probability of survival of victims.

There are several severity indexes that have been used in the results of research on trauma. These measures of scales have physiological, anatomical or mixed bases. Among anatomical ones, Injury Severity Score (ISS), created by Baker et. al in 1974 has been considered both over 20 years the "golden standard" to classify trauma victims, both blunt and penetrating. ISS is based on Abbreviated Injury Scale (AIS), a guideline of anatomical descriptors of wounds from trauma victims, which supplies for each lesion description an identifying number made up by 7 digits: the first digit identifies body region; the second represents type of anatomical structure; the third and fourth digits identify specific anatomical structure, or in cases of external surface lesions, the specific nature of the lesion; the fifth and sixth digits identify the level of lesion in a specific body region and anatomical structure; and the seventh digit to the right of decimal point is the AIS severity score identifier. This number may vary from 1 (minimal severity) to 6 (maximum severity, almost always fatal) ${ }^{(1)}$.

ISS, different from AIS, tries to portrait global severity of victims based on the severity score of lesions established by AIS. ISS is obtained by summing the square value of the 3 highest AIS scores, identifying severity of patients and enabling stratification of them. The greater the score value, the greater the severity of patient, and, consequently greater mortality ${ }^{(2)}$.

In 1997, authors of ISS changed this indicator because there was a flaw identified in its calculation, which considered a single lesion per body lesion, underestimating the severity of patients. In patients with multiple lesions located in the same body region, ISS considers only the most severe, ignoring the second most severe lesion that many times, is in the same body segment of the first. To correct these limitations the New Injury Severity Score (NISS) was created considering the three most severe lesions in the calculation, regardless of the body region ${ }^{(3)}$. This change from ISS to NISS aimed at increasing predictive value of the index and simplifying its calculation.

For 10 years, since the creation of NISS, the scientific community has assessed these two indexes, discussing which of the two indicators present best performance. In this context, the objectives of the present study are: describe the use of NISS in national and international research, and assess the results of the research that compared NISS with ISS.

\section{METHODS}

This is a descriptive, exploratory, study performed in Brazil, through a bibliographical review and made up of three phases. In the first phase a search for words in the data base Pubmed, Medline, Lilacs, and Scielo using the term NISS. The first search in these data base was performed in May 2006. To complete gathering investigations published in this year, a new search was performed in February 2007. Publications performed up to December 2006, both with adults and children were studied and the type of trauma was blunt or penetrating.

In the second phase, abstracts of all publications found in the previous phase were read focusing in the central issue and use of NISS. From reading the abstracts six groups were created to classify articles according to NISS contribution to the publication: NISS compared only with ISS; NISS compared with ISS and other severity indexes; NISS compared with other severity indexes; NISS indicating severity of sample; NISS inclusion criteria of victims in research and review of the literature. These categories have been consensually agreed on by the 
authors of the study before a second individual reading of this material was conducted, when publications were categorized according to NISS contribution to the investigation. Additionally, in this phase the following information were taken from abstracts: type of publication (research reported in journals, Doctorate theses or Master dissertation), year, language, place and journal of publication. After this stage was finished, individual observation of authors were examined and a diagnoses of the publications in the first stage was made.

The third stage of the work was restricted to analysis of articles that were classified in the categories of NISS compared only with ISS, and NISS compared with ISS and other severity indexes. This phase was made by reading and full assessment of all studies that approached these comparisons. The following information was gathered by this analysis: place of study, patients, type of trauma in the sample or population, diagnoses of the lesion, size, and size of sample, indicators of the studies compared, variables compared, and conclusions of the studies. Again, all classifications and categorizations of articles were examined and discussed by all authors of the present study.

Data collected were inserted onto an electronic spreadsheet of the Microsoft Office Excel 2003 program and organized into tables for better interpreting them.

\section{USE OF NISS IN NATIONAL AND INTERNATIONAL RESEARCH}

Forty-two studies were found, 39 research reports in journals, 1 literature review, 1 Master dissertation, and 1 Doctorate theses. Of the total of studies, $83.2 \%$ were indexed at Medline and Pubmed, $9.6 \%$ only at Pubmed, $4.8 \%$ at Lilacs, and only $2.4 \%$ at Scielo. Studies were published in 21 different journals; the greatest number of articles was published by The Journal of Trauma Injury, Infection and Critical Care (35.7\%), followed by Emergency Medicine Journal (7.1\%), Injury Prev, Journal of Orthopaedic Trauma and Journal American College Surgeons (4.7\% each). Among Brazilian journals, only Revista do Colégio Brasileiro de Cirurgiões (Journal of Brazilian College Surgeons) published an article addressing NISS ${ }^{(4)}$. Dissertation and thesis found were performed in Brazil ${ }^{(5-6)}$.
English was the prevalent publication language $(83.3 \%)$, followed by Portuguese $(7.1 \%)$, German, Czech, Danish, and Spanish (2.4\% each). There was predominance of studies performed in the USA $(23.8 \%)$, followed by Brazil and Canada $(9.5 \%$ each), England (7.1\%), Thailand, South Africa, Germany, and France (4.7\% each). One study was observed in each of the following countries: Denmark, Spain, Holland, Hungry, India, Iran, Iraq, Italy, New Zealand, Czech Republic, Israel, and Turkey. Thus, we could notice that the index has become of interest of the scientific communities in several countries.

The USA has the leadership in number of studies with the use of this new index, since it is the birth place of both NISS, and ISS, which are broadly used in large data base of trauma victims with the purpose of comparing results of care systems and estimate probability of survival of trauma patients. In Brazil, severity indexes of trauma are not part of the monitoring of accidents and violence in the country, however, the need for improving information on the accidents and violence to develop intervention strategies have enhanced the interest in these instruments in our environment.

Table 1 - Distribution of publications approaching NISS, according to the contribution of this indicator in the investigation and to publication year. Data base Scielo, Lilacs, Pubmed and Medline, 1997 to 2006

\begin{tabular}{|c|c|c|c|c|c|c|}
\hline \multirow{3}{*}{ NISS contribution to investigation } & \multicolumn{6}{|c|}{ Publication year } \\
\hline & 1997 & & 2001 & 2003 & 2005 & \\
\hline & 1998 & 2000 & 2002 & 2004 & 2006 & \\
\hline Comparison only with ISS & 2 & 1 & 6 & 4 & 2 & 15 \\
\hline Comparison with ISS and other indicators & - & - & - & 1 & 3 & 4 \\
\hline Comparison with other indicators & - & 1 & 1 & 1 & - & 3 \\
\hline Indicator of severity of the sample & - & - & 7 & 3 & 5 & 15 \\
\hline Inclusion criteria of victims in the research & - & - & - & 1 & 3 & 4 \\
\hline Review of the literature & - & - & - & - & 1 & 1 \\
\hline Total & 2 & 2 & 14 & 10 & 14 & 42 \\
\hline
\end{tabular}

The first NISS publication in 1997 already presented results of the comparison with ISS. In 1999, no studies were performed applying such index. However, as of 2000, the interest in testing NISS through comparison with other indexes started again; additionally, in 2001, its use as an indicator for severity of samples started. This application, although with a mild decrease in the following years, continued until 2006. Using NISS values as an inclusion criterion of victims in trauma research is more recent and was most commonly used in 2006.

The presence of studies that use NISS value as a criterion to describe severity of the sample or to 
include victims shows the confidence some researchers put on NISS over ISS. However, the great amount of recent research using ISS shows the preference of the scientific community for this index.

The only review of the literature found was from Germany, written in German and explains several severity indexes of trauma victims applied in the initial treatment and in the emergency room. There are advantages, disadvantages and limitations in the use of these indexes ${ }^{(7)}$. Of the total of 42 articles, 19 compared NISS with ISS: 15 compared only these two indexes, and 4 compared NISS with ISS and other indexes.

\section{RESEARCH THAT COMPARED NISS WITH ISS}

The 19 studies comparing NISS and ISS were assessed thoroughly by its full reading ${ }^{(3-5,8-23)}$. Of these, 18 concerned surveys reported in journals and 1 a Master dissertation. Comparison studies were performed in several world countries, with predominance of the USA (5), Canada (3), Brazil, and Thailand (2 each). Despite this diversity of countries, the USA had the greatest number of publication $(68.5 \%)$. Language of publication was English, 89.5\%, and Portuguese, 10.5\%. Regarding patients, it was identified that $36.9 \%$ of the studies focused the adult and children population, $47.4 \%$ only adult, and $15.7 \%$ children. This classification, followed that declared by authors in their texts, regardless of age group considered by them.

Table 2 - Distribution of studies that compared NISS and ISS, according to the size of sample/population and their extension. Data base Scielo, Lilacs, Pubmed, and Medline, 1997 to 2006

\begin{tabular}{lccc}
\hline \multicolumn{1}{c}{ Extension } & $<1,000$ cases & $\begin{array}{c}\text { Sample } \\
\mathbf{2 1 , 0 0 0} \text { and } \\
<10,000 \text { cases }\end{array}$ & $\geq 10,000$ cases \\
\hline Institutional & 4 & 7 & - \\
National Multicentric & 1 & 3 & 3 \\
Intemational Multicentric & - & - & 1 \\
\hline \multicolumn{1}{c}{ Total } & 5 & 10 & 4 \\
\hline
\end{tabular}

It is observed, on Table 2, that studies were institutional (11) or multicentric (8), and one of them was an international multicentric study. Size of samples ranged from 63 to 35,385 cases, and one of the multicentric studies domestically performed presented the greatest number of patients. Only $1 / 4$ of the research had sample lower than 1,000 cases. Regarding the focus of study, 15 studies approached
NISS and ISS exclusively, and 4 compared them with other indexes: Abbreviated Injury Scale - max (AISmax), Anatomic Profile (AP), Trauma and Injury Severity Score (TRISS), A Severity Characterization of Trauma (ASCOT), Abdominal Trauma Index (ATI), Glasgow Coma Scale (GCS), and Pediatric Trauma Score (PTS).

Several severity indexes have been developed in the last 30 years in trauma research, prevention and care, to give more accuracy to the instruments. Among them, AP as well as NISS, is an alternative index created because of the limitation of ISS and similarly because they propose a multidimensional characterization of trauma using AIS. AP was proposed in 1990 and considers all body lesions of the victim for its calculation, but in spite of that, the improvement in AP performance compared to ISS was only modest, and the complexity of AP application discourage broad acceptance of this index. The study comparing ISS with AP and NISS presents conclusions that point out better performance of these two indexes compared with ISS $^{(20)}$.

Most investigations focused on trauma victims in general (11) and among studies that assessed trauma with specific lesions, there was prevalence of musculoskeletal trauma (3), followed by brain trauma (2), chest and abdominal trauma (1), abdominal trauma undergoing laparotomy (1) and head, trunk and limbs injuries (1). Trauma has been also classified into blunt $(15.8 \%)$, penetrating $(10.5 \%)$, and both $(73.7 \%)$. Of the studies focusing only penetrating trauma, one of them considered only gunshot patients as inclusion criteria ${ }^{(11)}$.

Table 3 - Distribution of NISS and ISS comparisons, according to variables assessed and results observed. Data base Scielo, Lilacs, Pubmed, and Medline, 1997 to 2006

\begin{tabular}{lcc}
\hline \multicolumn{1}{c}{ Variables compared } & \multicolumn{2}{c}{ Comparison Results } \\
& $\begin{array}{c}\text { NISS superior to } \\
\text { ISS }\end{array}$ & $\begin{array}{c}\text { NISS equivalent to } \\
\text { ISS }\end{array}$ \\
\hline Sunvival & 8 & 6 \\
Rate of hospital stay & 2 & 3 \\
Referred to ICU & 2 & 1 \\
Sepses & - & 1 \\
Multiple organ dysfunction syndrome & 1 & 1 \\
Nosocomial infection & 1 & - \\
Post operative complications & 1 & - \\
Post trauma complications & - & 1 \\
Results / functional capacity & 2 & 1 \\
Transference to other hospitals & - & 1 \\
Situation at hospital discharge & - & 1 \\
\hline \multicolumn{1}{c}{ Total } & $\mathbf{1 7}$ & $\mathbf{1 6}$ \\
\hline
\end{tabular}


According to Table 3, NISS and ISS have been confronted with different variables: survival (yes or no), rate of hospital stay (number of days), admission to ICU (yes or no), sepses (yes or no), multiple organ dysfunction syndrome (yes or no), nosocomial infection (yes or no), postoperative complications (yes or no), post trauma complications (yes or no), results/ functional skill (dependent or independent), transference to other hospitals (yes or no) and situation at discharge (whether or not resources and/ or specific medical care were needed after hospital discharge $)^{(16)}$. Some studies compared more than one variable with ISS and NISS; others performed analysis of the total sample and specific groups of victims, such as severe, mild, closed and brain trauma. Analysis comparing ISS and NISS with survival were the most frequent and showed, in most publications, superiority of NISS. A similar result was observed regarding the variables: ICU admission, nosocomial infection, post operative complications and results/ functional capacity. NISS was not superior to ISS when rate of hospital stay, sepses, post trauma complications, transference to other hospitals, and situation at discharge were compared.

Table 4 - Distribution of studies comparing NISS and ISS, according to size of the sample and predictive value of NISS. Data base Scielo, Lilacs, Pubmed e Medline, 1997 to 2006

\begin{tabular}{|c|c|c|c|c|}
\hline \multirow[b]{2}{*}{ Predictive value } & \multicolumn{3}{|c|}{ Sample } & \multirow[b]{2}{*}{ Total } \\
\hline & $\begin{array}{l}<1,000 \\
\text { cases }\end{array}$ & $\begin{array}{c}\geq 1,000 \text { and } \\
<10,000 \text { cases }\end{array}$ & $\begin{array}{c}\geq 10,000 \\
\text { cases }\end{array}$ & \\
\hline NISS superior to ISS & 2 & 7 & - & 9 \\
\hline NISS equivalent to ISS & 3 & 2 & - & 5 \\
\hline $\begin{array}{l}\text { NISS superior to ISS at times, } \\
\text { and equivalent to ISS at times }\end{array}$ & - & 1 & 4 & 5 \\
\hline Total & 5 & 10 & 4 & 19 \\
\hline
\end{tabular}

According to Table 4, in studies with samples varying from 1,000 and 10,000 cases, most investigations presented favorable results to NISS. Samples greater than 10,000 indicated preference to NISS at times; other times they were the same depending on the event compared; samples lower than 1,000 showed more frequently equivalence between the indexes.

Although Table 3 shows 17 comparisons resulting in superiority of NISS in relation to ISS, and 16 showing equivalence. We can see in Table 4 that the number of publications favoring NISS is significantly greater: 9 compared to 5 that pointed out for equivalence among indexes.
As a final result, great part of the publications stated that NISS was more suitably related with studied variables than ISS, especially in severe and specific wounds (brain trauma). Additionally, studies pointing out for better performance of ISS have not been found.

We have observed that of the 14 studies including blunt and penetrating trauma, 8 stressed that NISS was a better predictor than ISS; 3 indicated equivalence between indexes and 3 showed superiority of NISS sometimes, and other times, equivalence depending on the variables compared. In blunt trauma, three studies have been conducted showing respectively: superiority of NISS, equivalence between indexes, or according to the variable approached, equivalence or superiority. The only two surveys focusing solely on penetrating trauma showed equality among the indexes, except for analysis comparing postoperative complications where NISS was a better predictor.

ISS and NISS use as a base for their calculation AIS, faults on this scale reflect on the performance of both indexes. Even though AIS has been developed at first to investigate the means to minimize wounds from motor vehicles, periodical review of their manual included and improved, since 1885, descriptions of trauma lesions in addition to those for car crash, making AIS better for the use in all types of external causes.

NISS presented greater frequency of favorable results when the type of patients was considered in surveys including adults or adults and children. There were no differences among indexes in studies where the population was exclusively children, except for a study presenting NISS as the best predictor of functional capacity in severe trauma. ISS was not better than NISS in any of the studies to predict events assessed; additionally, a publication highlighted the easiness of NISS application ${ }^{(23)}$.

\section{CONCLUSIONS}

Bibliographical review on research approaching NISS in the last ten years enabled the following observations.

OF the 42 studies found applying NISS, $83.3 \%$ was indexed in the data base Pubmed and Medline and published in the English language, most of them in the journal The Journal of Trauma Injury, Infection 
and Critical Care (35.7\%). Among the 20 countries of the different continents where researches have been conducted using NISS, the USA presented the greatest number of studies (10), followed by Brazil and Canada (4 in each country).

NISS, published in 1997, has been continuously tested comparing with ISS and other indexes. Research comparing ISS with NISS regarding variables that characterize the consequences of trauma, are favorable to the new version of the instrument, especially when they presented conclusions that showed the superiority of NISS and do not observe ISS outstripping NISS in its performance.

These evidences and the greater easiness to calculate NISS compared to ISS might have led to the replacement of ISS by NISS, however, 10 years after the proposal of change in the calculation of ISS, the scientific community is reticent, usually using ISS in their research and testing the new version of the instrument.

\section{REFERENCES}

1. Association for the Advancement of Automotive Medice AAAM. Abbreviated Injury Scale (AIS): 1990 revision. Des Plaines, Illions; 1990.

2. Baker SP, O'neill B, Haddon W, Long WB. The injury severity score: a method for describing patients with multiple injuries and evaluating emergency care. J Trauma 1974 March; 14(3): 187-96.

3. Osler T, Baker SP, Long W. A modification of the injury severity score that both improves accuracy and simplifies scoring. J Trauma 1997 December; 43(6):922-5.

4. Fraga GP, Mantovani M, Magna LA. Índices de trauma em pacientes submetidos à laparotomia. Rev Col Bras Cir 2004 Outubro; 31(5):299-306.

5. Campos, MA. O Injury Severity Score e a sua nova proposta em vítimas de trauma crânio-encefálico: diferenças em resultados e efetividade de valor preditivo. [dissertação]. São Paulo (SP): Escola de Enfermagem/USP; 2001.

6. Calil, AM. Dor e analgesia em vítimas de acidente de transporte atendidas em um pronto-socorro. [tese]. Säo Paulo (SP): Escola de Enfermagem/USP; 2003.

7. Kulla M, Fischer S, Helm M, Lampl L. [How to assess the severity of the multi-system trauma in the emergency-room - a critical review] Traumascores für den Schockraum - eine kritische Ubersicht. Anasthesiol Intensivmed Notfallmed Schmerzther 2005 December; 40(12):726-36.

8. Brenneman FD, Boulanger BR, McLellan BA, Redelmeier DA. Measuring injury severity: time for a change?. J Trauma 1998 April; 44(4):580-2.

9. Balogh Z, Offner PJ, Moore EE, Biffl WL. NISS predicts postinjury multiple organ failure better than the ISS. J Trauma 2000 April; 48(4):624-7.

10. Grisoni E, Stallion A, Nance ML, Lelli JL, Garcia VF, Marsh $E$. The New Injury Severity Score and the evaluation of pediatric trauma. J Trauma 2001 June; 50(6):1106-10.

11. Streng M, Tikka S, Leppäniemi A. Assessing the severity of truncal gunshot wounds: a nation-wide analysis from Finland. Ann Chir Gynaecol 2001 November; 90(4):246-51. 12. Jamulitrat $S$, Sangkerd $P$, Thongpiyapoom $S$, Na Narong M. A comparison of mortality predictive abilities between NISS and ISS in trauma patients. J Med Assoc Thai 2001 October; 84(10): 1416-21.
13. Jamulitrat S, Narong MN, Thongpiyapoom S. Trauma severity scoring systems as predictors of nosocomial infection. Infect Control Hosp Epidemiol 2002 May; 23(5):268-73.

14. Husum H, Strada G. Injury Severity Score versus New Injury Severity Score for penetrating injuries. Prehospital Disaster Med 2002 January-March; 17(1):27-32.

15. Balogh ZJ, Varga E, Tomka J, Süveges G, Tóth L, Simonka JA. The new injury severity score is a better predictor of extended hospitalization and intensive care unit admission than the injury severity score in patients with multiple orthopaedic injuries. J Orthop Trauma 2003 August; 17(7):508-12.

16. Sullivan T, Haider A, DiRusso SM, Nealon P, Shaukat A, Slim $M$. Prediction of mortality in pediatric trauma patients: new injury severity score outperforms injury severity score in the severely injured. J Trauma 2003 December; 55(6):1083-7.

17. Tay SY, Sloan EP, Zun L, Zaret P. Comparison of the New Injury Severity Score and the Injury Severity Score. J Trauma 2004 January; 56(1):162-4.

18. Lavoie A, Moore L, Lesage N, Liberman M, Sampalis JS. The New Injury Severity Score: a more accurate predictor of in-hospital mortality than the Injury Severity Score. J Trauma 2004 June; 56(6):1312-20.

19. Lavoie A, Moore L, LeSage N, Liberman M, Sampalis JS. The Injury Severity Score or the New Injury Severity Score for predicting intensive care unit admission and hospital length of stay?. Injury 2005 April; 36(4):477-83.

20. Frankema SP, Steyerberg EW, Edwards MJ, van Vugt AB. Comparison of current injury scales for survival chance estimation: an evaluation comparing the predictive performance of the ISS, NISS, and AP scores in a Dutch local trauma registration. J Trauma 2005 March; 58(3):596-604. 21. Sutherland AG, Johnston AT, Hutchison JD. The new injury severity score: better prediction of functional recovery after muscoloskeletal injury. Value Health 2006 January-February; 9(1):24-7.

22. Harwood PJ, Giannoudis PV, Probst C, Van Griensven M, Krettek C, Pape HC. The Polytrauma Study Group of the German Trauma Society. Which AIS based scoring system is the best predictor of outcome in orthopaedic blunt trauma patients?. J Trauma 2006 February; 60(2):334-40.

23. Bulut M, Koksal O, Korkmaz A, Turan M, Ozguc H. Childhood falls: characteristics, outcome, and comparison of the Injury Severity Score and New Injury Severity Score. Emerg Med J 2006 July; 23(7):540-5. 